\title{
Simulation and Control Lab Development for Power and Energy Management for NASA Manned Deep Space Missions
}

\author{
Anne M. McNelis ${ }^{*}$ and Raymond F. Beach ${ }^{\dagger}$ \\ NASA Glenn Research Center, Cleveland, Ohio, 44135 \\ James F. Soeder ${ }^{\ddagger}$ and Nancy B. McNelis ${ }^{\S}$ \\ NASA Glenn Research Center, Cleveland, Ohio, 44135 \\ Ryan May" \\ Vantage Partners LLC, Cleveland, Ohio, 44142 \\ and \\ Timothy P. Dever ${ }^{\#}$ and Larry Trase ${ }^{* *}$ \\ NASA Glenn Research Center, Cleveland, Ohio, 44135
}

$\begin{array}{ll} & \\ \text { AMPS } & =\text { Advanced Modular Power Systems } \\ \text { AES } & =\text { Advanced Exploration Systems } \\ \text { ISS } & =\text { International Space Station } \\ \text { EPS } & =\text { Electrical Power System } \\ \text { NASA } & =\text { National Aeronautics and Space Administration } \\ \text { GRC } & =\text { Glenn Research Center } \\ \text { ASMG } & =\text { Automated State Model Generator } \\ \text { DHS } & =\text { Distributed Heterogeneous Simulation } \\ \text { SIL } & =\text { Software in the Loop } \\ \text { HIL } & =\text { Hardware in the Loop } \\ \text { PSF } & =\text { Power Systems Facility } \\ \text { PMAD } & =\text { Power Management and Distribution } \\ \text { RSIL } & =\text { Radio-Isotope Stirling Integration } \\ \text { SNRF } & =\text { Space Network Research Federation } \\ \text { RPC } & =\text { Remote Power Controller } \\ \text { RBI } & =\text { Remote Bus Isolator } \\ \text { MBSU } & =\text { Main Bus Switching Unit } \\ \text { PDU } & =\text { Power Distribution Unit } \\ \text { SSU } & =\text { Sequential Shunt Unit } \\ \text { BCDU } & =\text { Battery Charge Discharge Unit } \\ \text { DCSU } & =\text { DC Switching Unit }\end{array}$

\footnotetext{
*Aerospace Engineer, 21000 Brookpark Road, anne.m.mcnelis@nasa.gov

${ }^{\dagger}$ Electrical Engineer, 21000 Brookpark Road, raymond.f.beach@nasa.gov

*Electrical Engineer, 21000 Brookpark Road, james.f.soeder@nasa.gov

§ Aerospace Engineer, 21000 Brookpark Road, nancy.b.mcnelis@nasa.gov

" Controls Engineer, 3000 Aerospace Parkway, ryan.d.may@nasa.gov, AIAA Member.

\# Electrical Engineer, 21000 Brookpark Road, timothy.p.dever@nasa.gov

${ }^{* *}$ Electrical Engineer, 21000 Brookpark Road, larry.trase@nasa.gov
} 


\begin{abstract}
The development of distributed hierarchical and agent-based control systems will allow for reliable autonomous energy management and power distribution for on-orbit missions. Power is one of the most critical systems on board a space vehicle, requiring quick response time when a fault or emergency is identified. As NASA's missions with human presence extend beyond low earth orbit, autonomous control of vehicle power systems will be necessary and will need to reliably function for long periods of time. In the design of autonomous electrical power control systems there is a need to dynamically simulate and verify the Electrical Power System (EPS) controller functionality prior to use on-orbit. This paper presents the work at NASA Glenn Research Center in Cleveland, Ohio where the development of a controls laboratory is being completed that will be utilized to demonstrate advanced prototype EPS controllers for space, aeronautical and terrestrial applications. The control laboratory hardware, software and application of an autonomous controller for demonstration with the ISS electrical power system is the subject of this paper.
\end{abstract}

\begin{abstract}
A needed to attain reliable power and energy management on-orbit. Meeting the power demands and responding to faults or emergencies within a space vehicle's power system requires quick response times. The ground support communication latency time in a deep space habitat environment is estimated to be as much as 45 minutes. With an intelligent power system controller coordinating the electrical power system energy management actions, and resolving anomalous system behavior, a more rapid response will benefit deep space mission operations and increase safety of the crew.

The use of advanced hardware and control technology can be utilized to autonomously manage and control distributed power generation and storage assets, power distribution networks, and loads for space exploration systems. With a human presence in deep space missions, intelligent power systems will have stringent requirements for their operation to assure human safety. Some of the key requirements revolve around safely managing and controlling the energy generation, storage devices, and power distribution systems. The power system will be required to provide multiple years of autonomous quiescent operations in-between habitations. At the same time, the power system and controllers will allow crew consent as needed for operations or actions during habitation. With the cooperation of a vehicle-level mission manager, power system controllers can be developed to advise and consent on loads management, anomalous event corrective action and health of the power system. A necessary capability in the development of these controls is the ability to exercise them over an extensive set of operational scenarios to insure that they will provide robust performance across their entire range of expected operation. To meet the development objectives it is necessary to have a control development environment, with a high fidelity real-time simulation of the power system, enabling development, rapid prototyping, and verification / validation of the control algorithms.

The authors are developing a controls laboratory environment, consisting of a cluster of computer workstations with multiple cores, on which reside the Automated State Model Generator (ASMG) and Distributed Heterogeneous Simulation (DHS) patented ${ }^{1,2}$ software developed by PC Krause and Associates. The DHS software allows for the decomposition and distribution of power components and subsystems, modelled in Matlab/Simulink, across the cores and workstations enabling real time simulation. Also included in the development environment are electronic benches for build up and test of the Rockwell PLC controller hardware used to host the reactive control for the power system regulators and switchgear protective functions. This laboratory capability will allow real-time simulations of electrical power systems for software and hardware in the loop control development activities. Prototype hardware testbeds are also under development at the NASA Glenn Research Center (GRC) which will represent future vehicle power systems for use in verification and validation of the power control algorithms. The laboratory has the capability to demonstrate multiple vehicle power systems, with multiple power busses in each vehicle, all operating with real-time control simulations for the autonomous control development. The laboratory is currently used to demonstrate distributed hierarchical control for energy and power management using agent based software control algorithms. This paper will provide a description of the control lab software and hardware, performance goals, and expected development efforts.
\end{abstract}




\section{PCKrause EPS Power ASG/DHS Simulation Software}

The International Space Station (ISS) is the largest and most complex space power system, incorporating eight power channels to enable power generation, storage, distribution, and load management. Characteristics of the ISS power system, such as energy generation and storage, power flow and sharing between power channels, and a large diversity factor is typical of a terrestrial utility power system. The ISS was designed to operate more like a utility power system in order to simplify operational oversight and achieve high power availability for both scientific and critical infrastructure loads. On orbit operation and power system experience with the ISS has demonstrated the benefits of the multi-channel power architecture and is a point of departure architecture for the expected manned deep space missions. Extensive data from ISS operations is also utilized to develop and validate the power component and element models, as well as the operation scenarios for the real-time simulations.

Utilizing the PC Krause DHS software and Simulink based component ASMG models, such as batteries, solar arrays, regulators, and switching units, the power system simulations for the mission vehicles can be constructed. These constructs are then used to conceptualize and develop the control hierarchy and power control algorithms.

Working through a Small Business Innovative Research (SBIR) contract with NASA, PC Krause and Associates of West Lafayette, Indiana are developing electrical power system (EPS) component models for NASA's spacecraft power system simulations. The power components will reside in a Matlab/Simulink ASMG library and include models for the solar arrays, batteries, array and battery regulators, power distribution and switching units, secondary and load converters, and various types of loads. All power component models were validated using ISS data, and system simulations of the ISS and other AES power systems were interconnected using the library models. These multiple channel dynamic simulations were used to verify the system level simulations, and provide performance data to allow for real time operation.

Development of the higher level control requires component models that have appropriate dynamics to represent the power component and the reactive control associated with its automatic operation. For regulator components, such as the battery charge/discharge unit which utilizes a bilateral buck boost switching topology, an average model for the converter representing the voltage transformation can be used in conjunction with the feedback control. Input and output filter components are also included in the model to obtain impedance matching over the dynamic operating range for the converter. For protective devices, such as remote power controllers and remote bus isolators used for load activation and distribution protection, the trip function is implemented along with a simplified model of the protective switching device. This provides suitable dynamic representation of the power system at the sampling frequency used for the high level controls.

To maintain real time simulation requires the use of average models for the switchmode power converters used for system and load regulation. Average value models of the ISS EPS are being created by PC Krause that will increase modelling efficiency and run time as the moving average of the power system quantities for voltages and currents are developed in these models. The PC Krause Automated State Model Generator (ASMG) is employed allowing the graphical development of the switchmode converter equations and can be used to obtain the model for any power electronic topology. The ASMG approach provides a fast and accurate realization of the EPS models developed by automatically reducing the number of state variables in the circuit representation and determining the correct switch state of components ${ }^{3}$. Real-time dynamic simulations of the EPS are possible using the ASMG models in conjunction with the DHS software that allows for the decomposition of the system model for distribution in the various cores and workstations in the development lab.

Figure 1 is a representation of the assembly of the power elements to configure a representation of 8 channels of the ISS EPS that is shown in Figure 2. The electrical circuit elements are paired to develop smart components which are then integrated to form the vehicle level electrical power system representation used in simulation and controller development. In Figure 3 an example of a single channel of the ISS EPS is developed by PC Krause utilizing the ASMG EPS library elements. 


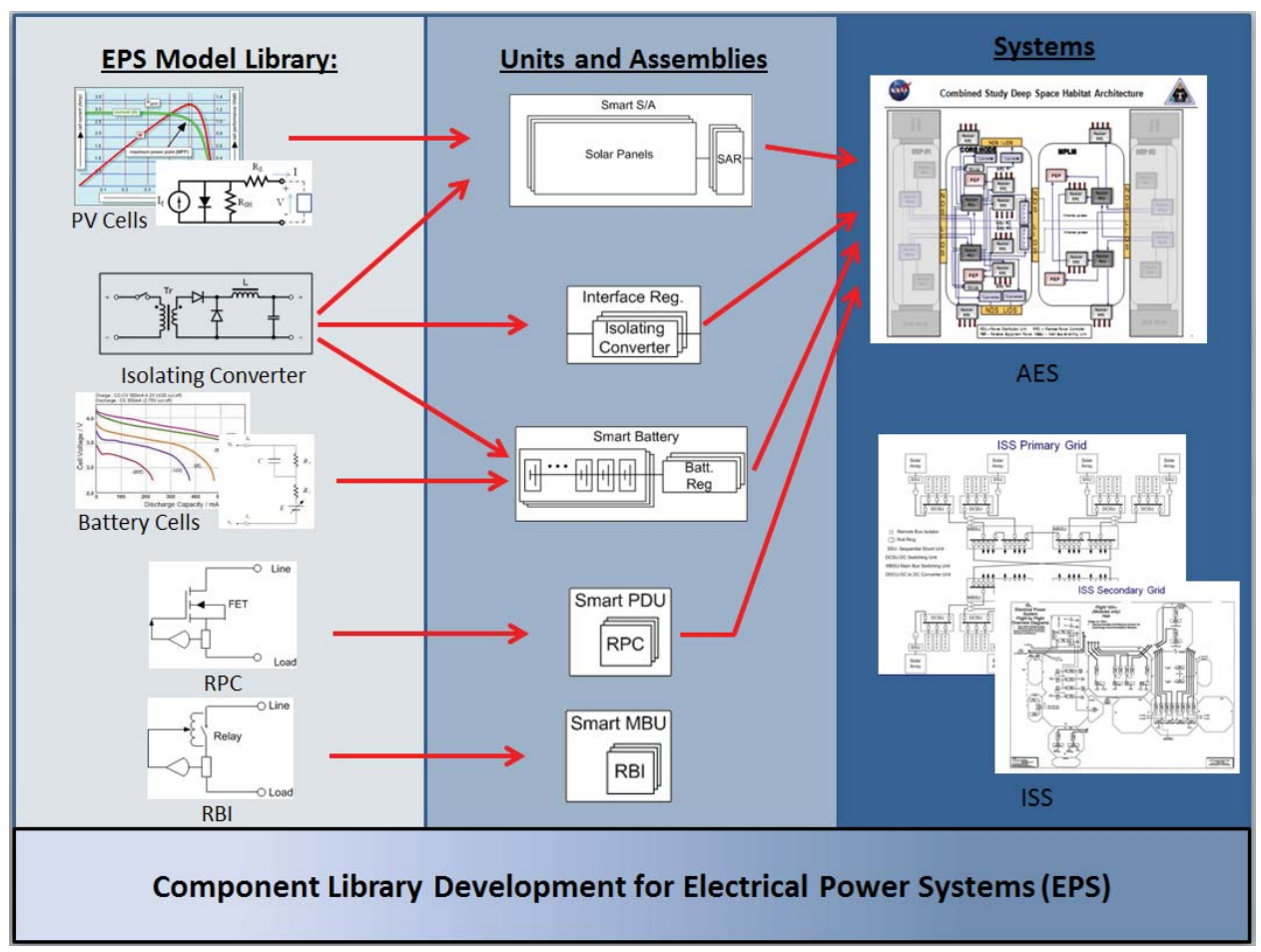

Figure 1. Electrical Power System Model Component Integration for Spacecraft Simulation

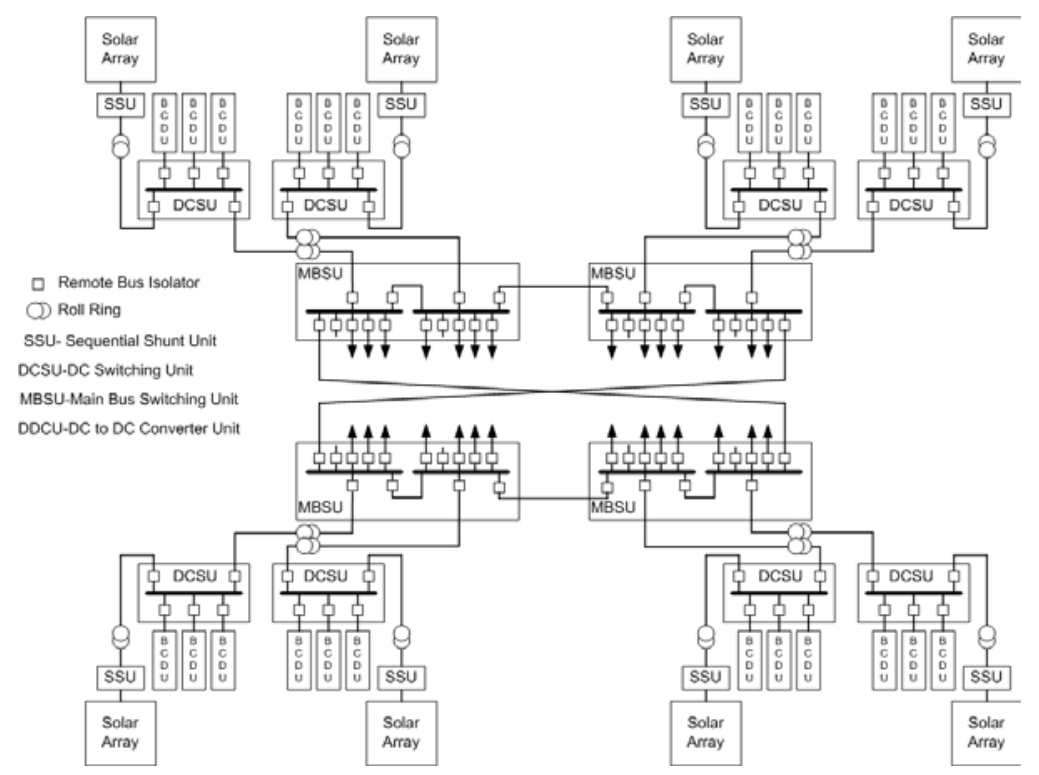

Figure 2. International Space Station EPS Architecture 


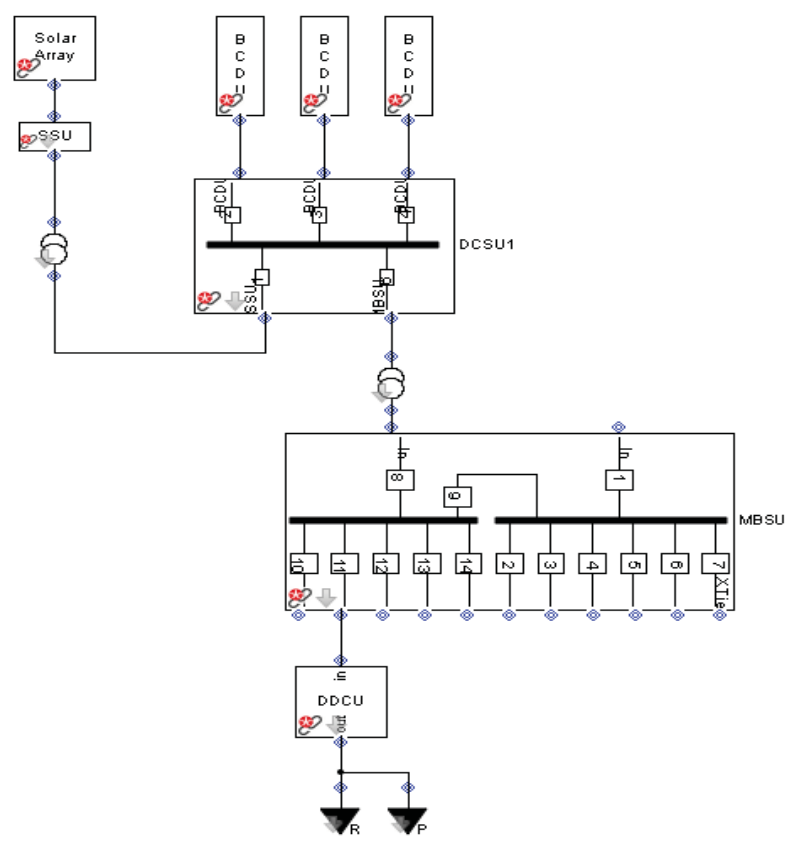

Figure 3. Single Channel of the International Space Station Modelled in ASMG

The Distributed Heterogeneous Simulation (DHS) software patented by PC Krause ${ }^{3}$ enables the development of multiple channels of spacecraft electrical power systems such as the ISS. The DHS software allows for synchronization of any number of interconnected dynamical subsystem simulations and provides a faster than real time simulation ${ }^{4}$. These simulations can be combinations of various programs, such as Satellite Tool Kit (STK) which can provide spacecraft attitude and orbit vectors that affect solar array output; Sinda for thermal, and C-code or other custom built model and analysis tools that are implemented on workstations, intranet, and distributed computer networks (internet).

At the NASA GRC the ASMG and DHS PC Krause software, along with the STK software from AGI, are being utilized to develop energy management and advanced power control algorithms, using the ISS as a target application. The intelligent power management control can then be overlayed on the modular power system elements, being developed on the Advanced Modular Power Systems (AMPS) program, to allow NASA to construct the future deep space EPS simulations. NASA GRC has developed a controls laboratory at GRC that will allow for the development and validation of the advanced controls for energy management of Software In the Loop (SIL) and Hardware in the Loop (HIL) electrical power system demonstrations prior to deployment in a future space vehicle ${ }^{5,6}$. To demonstrate the feasibility of such a system, GRC is simulating the eight channels of the primary and secondary ISS EPS, and developing advanced autonomous agent technology to control the energy management of the EPS. The GRC laboratory hardware includes eight PC workstations that will each run one channel of the ISS EPS simulation using the PC Krause Simulink based software for ASMG and DHS. The DHS software will be configured to interconnect each of the eight channels for co-simulation with a better than real time simulation capability. The following section describes the Intelligent Power Management Development Lab at the NASA GRC.

\section{Intelligent Power Management Development Lab}

The NASA GRC has been the agency lead center for energy conversion due to its heritage work on aircraft propulsion in the 1950s. Throughout the 1960s and 1970s the energy conversion role expanded to include work focused on the conversion of energy and power for both aircraft and spacecraft applications. From an energy conversion perspective this involved technology development for collection and conversion of solar energy through photovoltaic or thermal conversion, and for nuclear sources the conversion of thermal energy into electrical power. From a power perspective this included work on the technology and development of power electronic regulators and distribution protection devices for power management. With the start of the space station development in the 1980s, 
and the eventual flight hardware development and integration to complete the ISS in the early 2000s, the Center's role expanded to include power systems technology and development.

In order to support the power systems work at the GRC a Power Systems Facility (PSF), shown in Figure 4, was constructed to enable testing of power technologies and flight hardware elements needed for the ISS. Within the PSF, there are testing areas that support Power Management and Distribution (PMAD) and power systems technology and developmental work. Power system testing for the ISS utilized multiple test cells to properly represent the physical dimensions of the distribution system and accommodate the connections to the solar array field located next to the PSF. Cold plate tables used to simulate thermal interfaces, power supplies for control power and simulated source power, and energy storage and load simulators were developed to support the ISS power system testing. All electrical, cooling, and system support hardware were wired and plumbed to allow for reconfiguration of the facility to support all future power system testing.

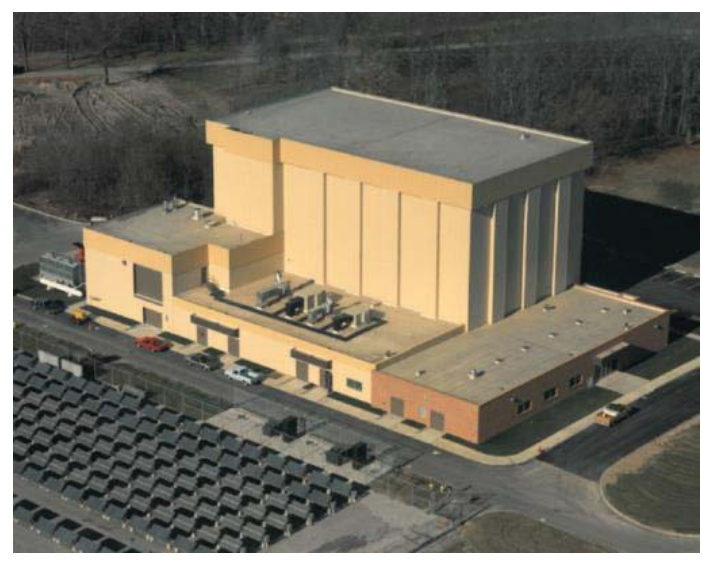

Figure 4. GRC Power Systems Facility (PSF)

Following completion of the ISS, the PSF and ISS testbed hardware were re-purposed to support the development of the Orion capsule and service module. Figure 5 shows the Orion testbed, and Figure 7 is a schematic diagram of the testbed, showing the sources, energy storage, distribution system and loads used for developmental testing and model/simulation validation of the Orion vehicle. Located adjacent to the Orion testbed is the Radio-isotope Stirling Integration (RSIL) testbed shown in Figure 6. The RSIL testbed was constructed to verify and validate the avionics and control for the Stirling power conversion system, used in conjunction with a radio-isotope source for deep space unmanned mission applications.

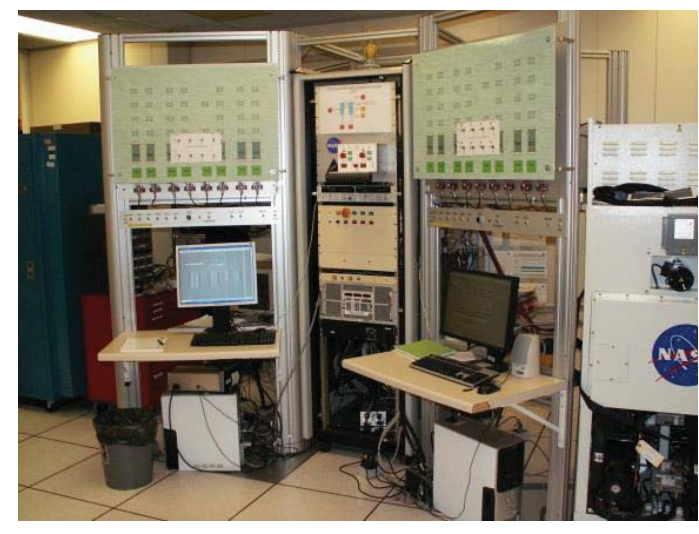

Figure 5. Orion Testbed

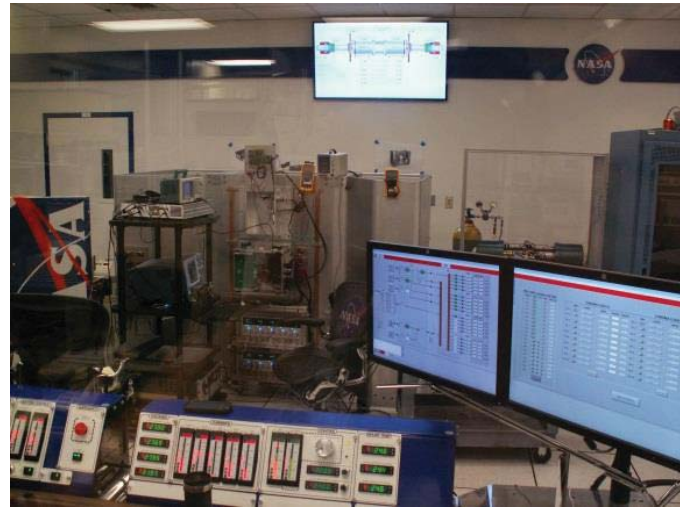

Figure 6. Radio-isotope Stirling Integration Lab 


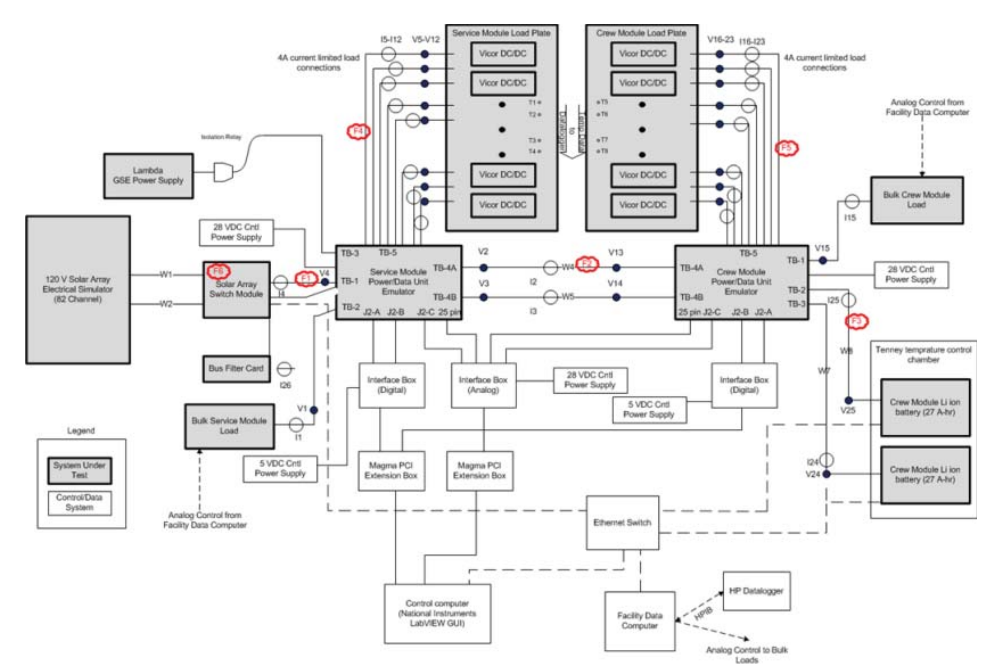

Figure 7. Orion Power and Control Schematic

Located adjacent to the RSIL and Orion testbeds is the intelligent control and simulation lab, shown in Figure 8. The location for the intelligent control and simulation lab was driven by the need to have close proximity to the testbeds for sensor and control signal access through a connecting raised floor. Multi-functional top level requirements for the controls test lab include simulation development and real time simulation using a workstation network, and control algorithm and controller hardware development using smart boards, workstations, and benches. The last top level requirement is higher level control operation for testbeds simulating space system operations and control operations for the planned GRC 300 area smart grid ${ }^{7}$.
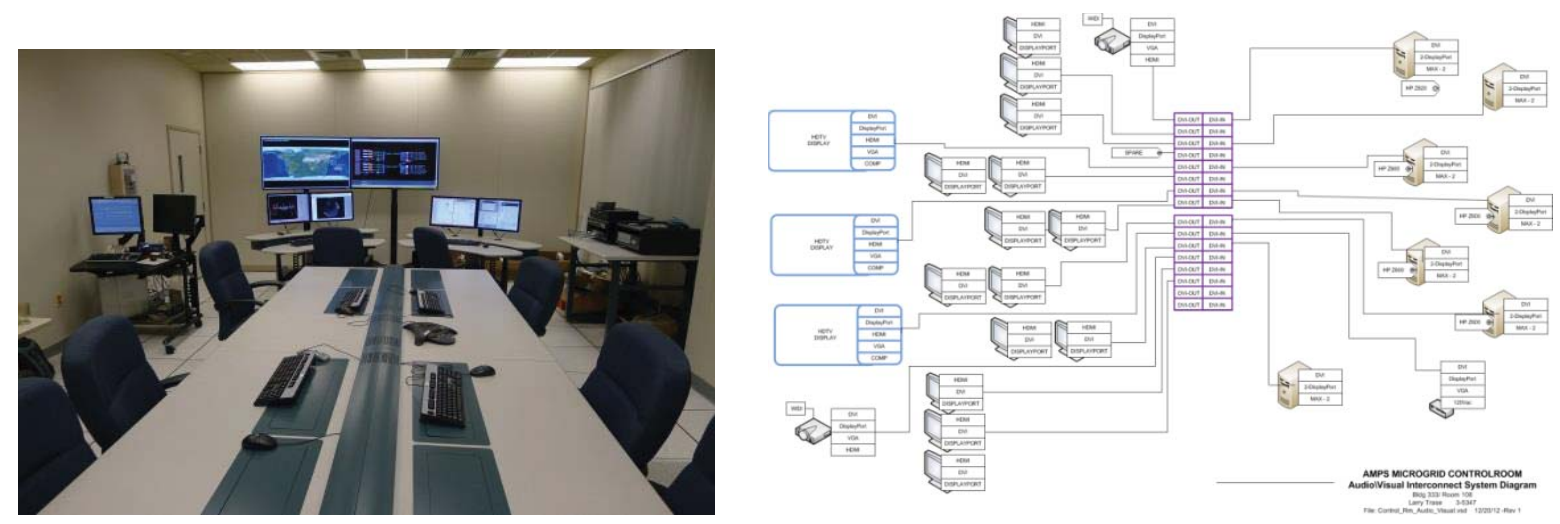

Figure 8. Intelligent Power Management Development Lab and Schematic Diagram

Planning is underway for the re-purposing of the Orion testbed hardware to enable an initial capability representing the multi-vehicle configuration expected for manned exploration missions. As described earlier, the Orion testbed hardware represented both the Orion capsule and the service module with no requirement for electrical isolation. Introduction of isolating power electronic regulators and additional solar array and battery functionality enables a two vehicle capability. An intelligent EPS control developed at NASA GRC in Cleveland, OH, will interface with the Mission Manager at NASA Ames, located in Mountain View, CA, through the Space Network Research Federation (SNRF) to control EPS HIL at NASA Johnson Space Center, located in Houston, TX, as shown in Figure 9.

As described in section II, the STK software is run as part of the software simulation to obtain ISS eclipse orbit information, while the DHS software is used for integration and time synchronization. Visualization of the simulation data and control actions used to achieve power management, fault detection, and isolation is achieved with Ignition software. 


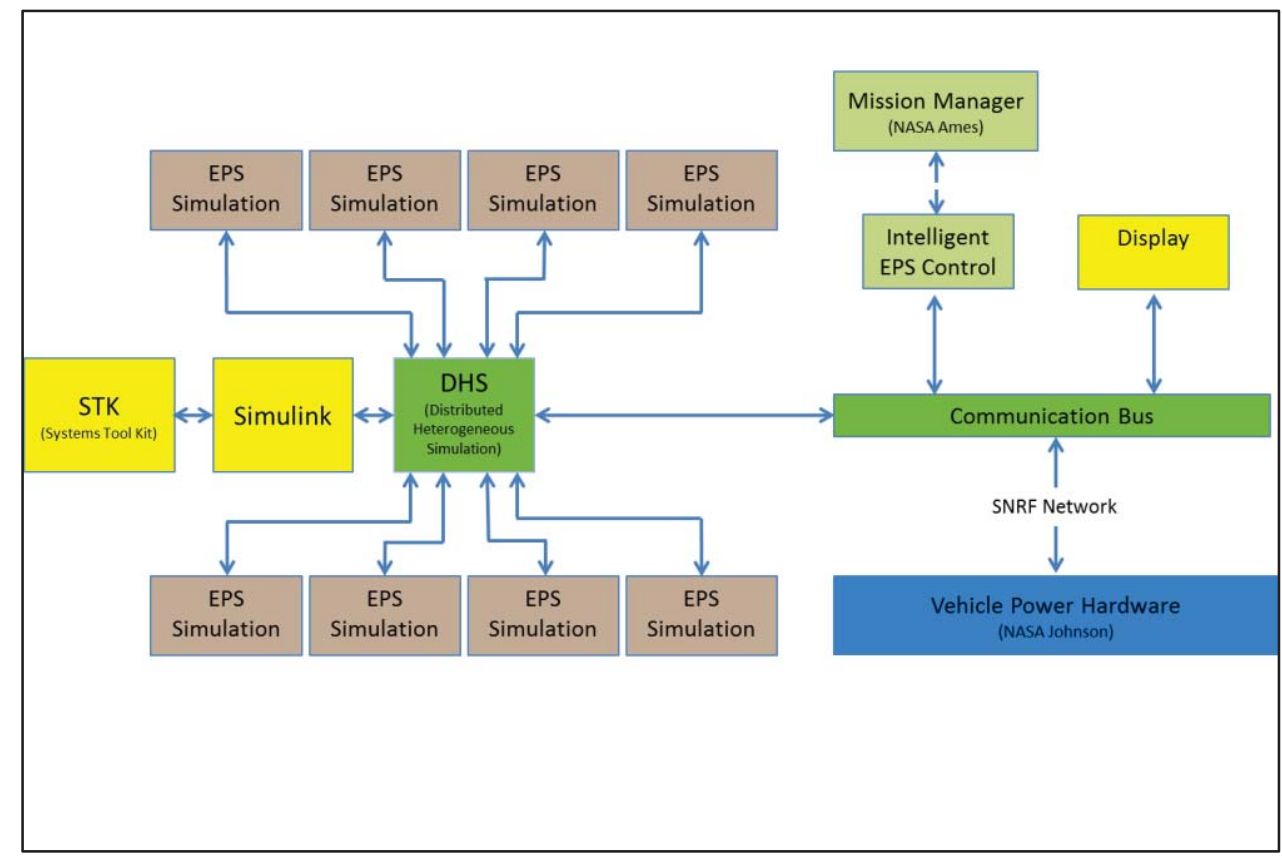

Figure 9. Eight channel ISS EPS Simulation with Intelligent EPS Control

In addition to the re-purposing of the Orion testbed, NASA GRC is evaluating the potential for a smart grid for the GRC 300 area. Expected synergies with the intelligent/autonomous space power system control, needed for the manned deep space missions, would provide initial control algorithms to enable control and operation of the planned smart grid. The controls test cell will then function as the control center for smart grid oversight and operation using the Ignition software for display and control changes.

\section{Conclusion}

As NASA's missions extend beyond low earth orbit the need to autonomously manage the power systems of deep space vehicles will become increasingly necessary. The author's work in developing a control simulation laboratory, re-purposing plans for the Orion Test bed and advancing the real-time electrical power system simulation capability of vehicle power systems will aid in the successful development of NASA's deep space vehicles. Manned deep space missions will require multiple launches with multiple vehicles docked together which will require integration of multiple segments that must exchange power harmoniously. All vehicles will utilize modular power components to construct the individual power system for each of the required vehicles. The methodology being developed at NASA GRC to develop and validate the intelligent/autonomous control system algorithms, used in each of the vehicles, will exploit simulations for both software and hardware in the loop testing, and power system testbeds to fully demonstrate the safe operation of power management system controls.

\section{References}

${ }^{1}$ Wasynczuk, O., Jatskevich, J.V., “Circuit Simulation,” US Patent, 7353157 B2, 2008.

${ }^{2}$ Wasynczuk, O., Lucas, C., Walters, E., Jatskevich, J., "Distributed Simulation,” US Patent 7490 029, Feb. 10, 2009.

${ }^{3}$ Wasynczuk, O., Sudhoff, S.D., "Automated state model generation algorithm for power circuits and systems," Power Systems, IEEE Transactions on, vol. 11, no. 4. pp. 1951-1956, Nov 1996.

${ }^{4}$ Loop, B., Lucas, C., Walters, E., Hasan, M., Field, S., Kumbar, N., "Improvements in the Distributed Heterogeneous Simulation of Aircraft Electric Power Systems," 2006 SAE Power Systems Conference Proceedings, 2006-01-3044, Nov. 2006, New Orleans, LA.

${ }^{5}$ May, Ryan D., Dever, Timothy P., Soeder, James F., George, Patrick J., Morris, Paul H., Colombano, Silvano P., Frank, Jeremy D., Schwabacher, Mark A., Wang, L., Lawler, Dennis., "An Architecture to Enable Autonomous Control of Spacecraft", to be published at IECEC, Cleveland, OH, July 28-30, 2014.

${ }^{6}$ Soeder, J.F., Dever, T.P., McNelis, A.M., Beach, R.F., Trase, L.M., May, R.D., "Overview of Intelligent Power Controller Development for Human Deep Space Exploration”, to be published at IECEC, Cleveland, OH, July 28-30, 2014.

${ }^{7}$ Dever, T.P., Trase, L.M., Soeder, J.F., “Application of Autonomous Spacecraft Power Control Technology to Terrestrial Microgrids", to be published at IECEC, Cleveland, OH, July 28-30, 2014. 